Supplement of Hydrol. Earth Syst. Sci. Discuss., 12, 1119-1153, 2015

http://www.hydrol-earth-syst-sci-discuss.net/12/1119/2015/

doi:10.5194/hessd-12-1119-2015-supplement

(C) Author(s) 2015. CC Attribution 3.0 License.

(c) (1)

Supplement of

\title{
Global warming increases the frequency of river floods in Europe
}

L. Alfieri et al.

Correspondence to: L. Alfieri (lorenzo.alfieri@jrc.ec.europa.eu) 


\section{Supplementary figures}

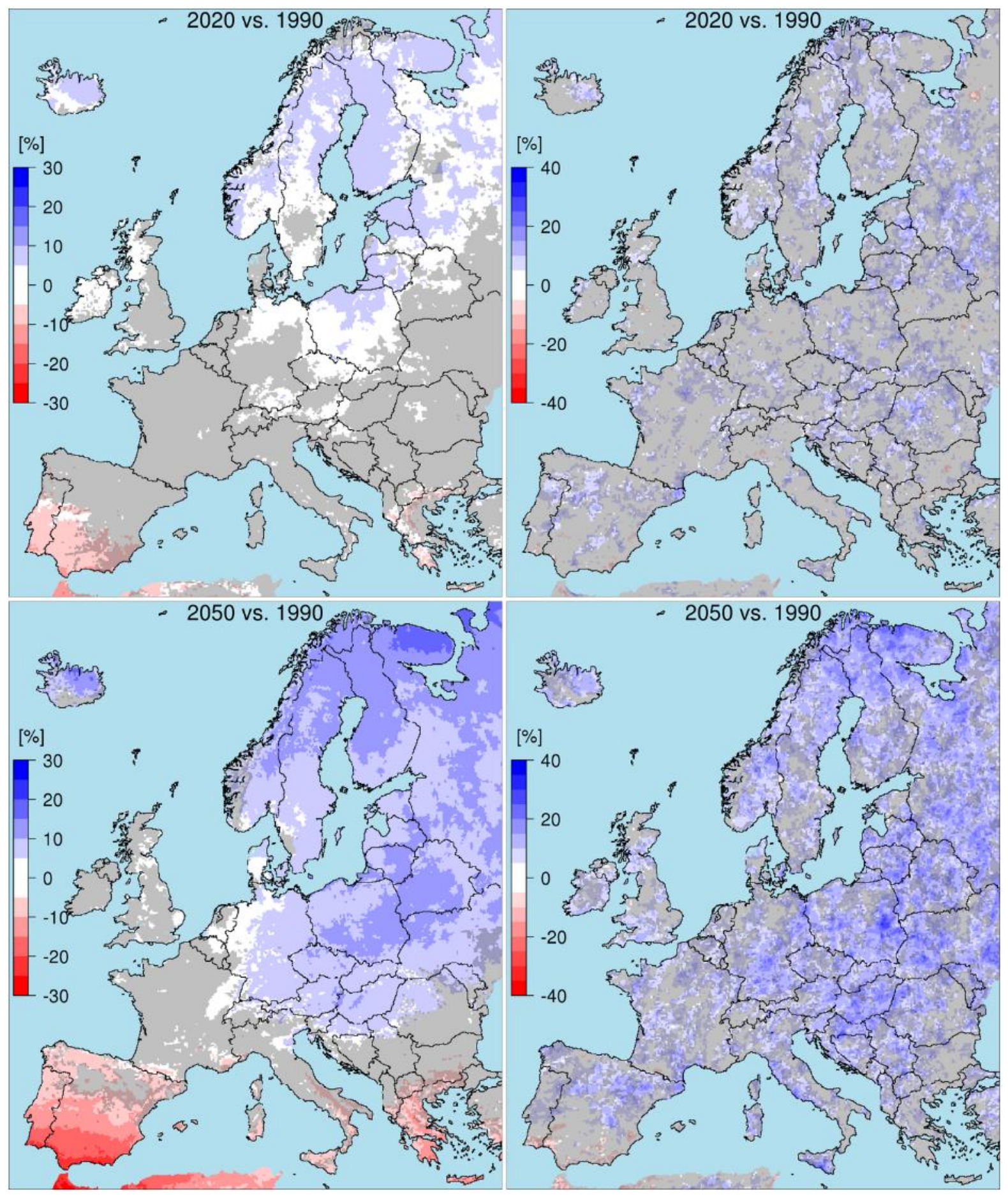

Figure S1: Relative change in annual precipitation (pryear, left) and annual maximum daily precipitation ( $\mathrm{pr}_{\mathrm{MAX}}$, right) for the time slice 2006-2035 (top) and 2036-2065 (bottom). Data points with CV>1 are greyed out. 

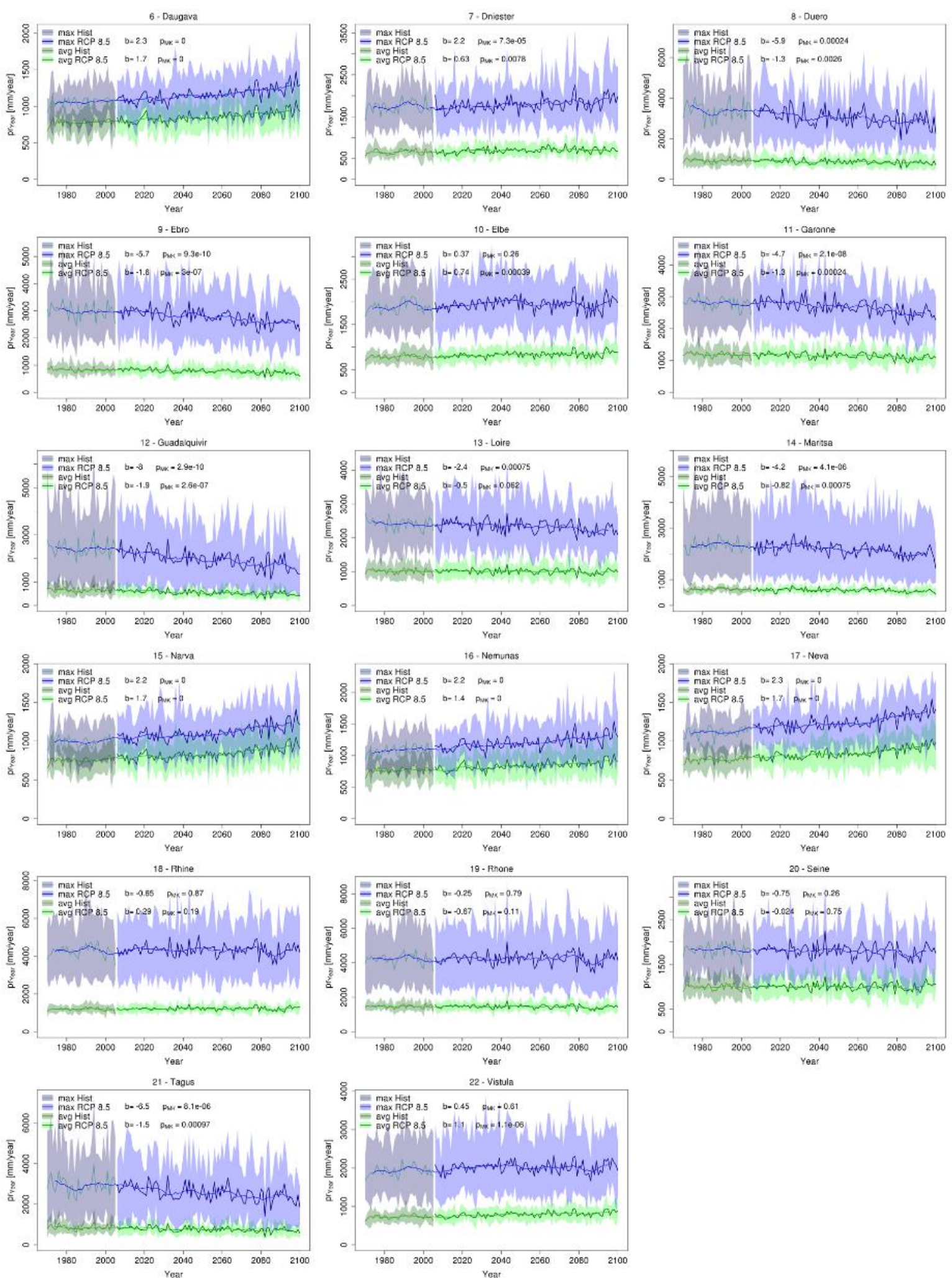

Figure S2: Annual precipitation total (pryear) for selected European river basins over time. Basins location is shown in Figure 1 (in yellow). Basin average (green shades) and maximum point value (blue shades) of the ensemble are shown together with the ensemble mean (thick lines) and the 10-year average (thin lines). 

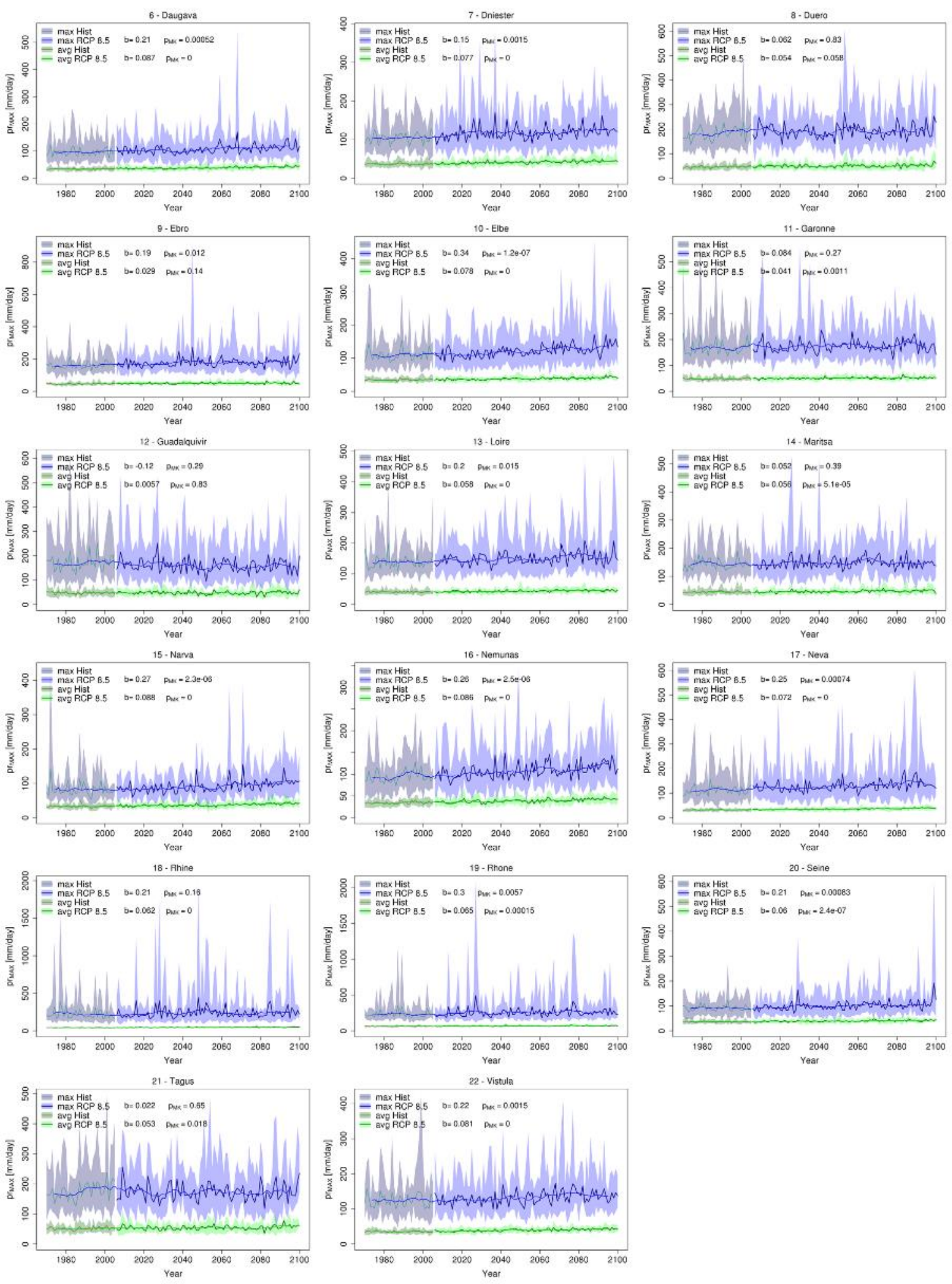

Figure S3: Annual maximum daily precipitation $\left(\mathrm{pr}_{\mathrm{MAX}}\right.$ ) for selected European river basins over time. Basins location is shown in Figure 1 (in yellow). Basin average (green shades) and maximum point value (blue shades) of the ensemble are shown together with the ensemble mean (thick lines) and the 10-year average (thin lines). 


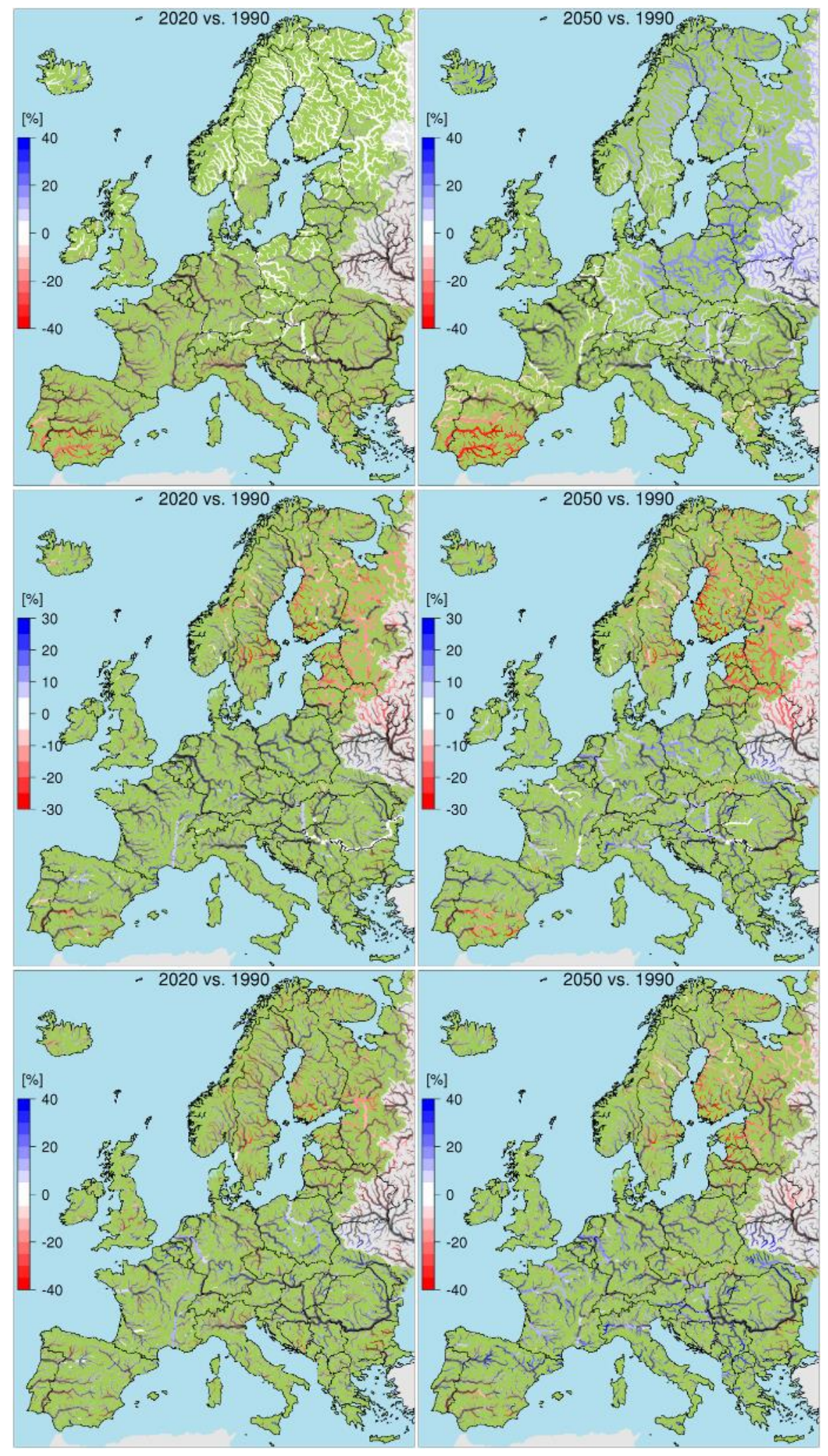

Figure S4: Relative change in average streamflow $\bar{Q}$ (top), mean annual daily peak flow $\overline{Q_{\mathrm{MAX}}}$ (center) and 100-year daily peak flow $Q_{100}$ (bottom) for the time slice 2006-2035 (left) and 2036-2065 (right). Data points with $\mathrm{CV}>1$ are greyed out. 

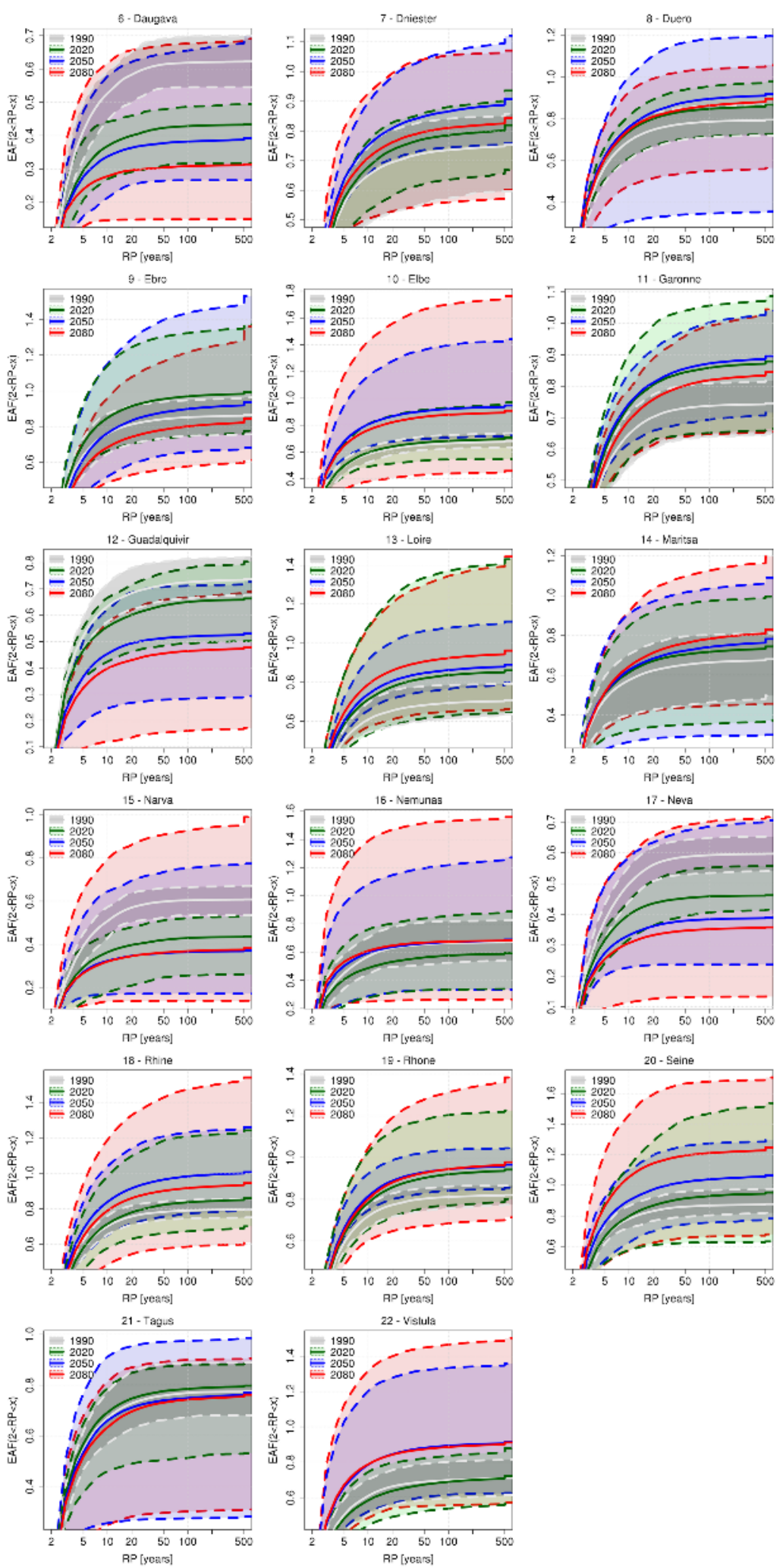

Figure S5: Expected annual frequency of peak flows with return period larger than 2 years for selected European river basins (see location in Figure 1) for the baseline simulation and the three future time slices. 